\title{
Critical level interaction of a gravity wave with background winds driven by a large-scale wave perturbation
}

\author{
Mitsumu K. Ejiri, ${ }^{1,2}$ Michael J. Taylor, ${ }^{1}$ Takuji Nakamura, ${ }^{3}$ and Steven J. Franke ${ }^{4}$ \\ Received 30 October 2008; revised 7 February 2009; accepted 13 April 2009; published 24 September 2009.
}

[1] As part of the Maui-Mesosphere and Lower Thermosphere program, data from the Utah State University Mesospheric Temperature Mapper (MTM) and the University of Illinois Meteor Wind Radar (MWR) have been used to investigate wave-driven dynamical interactions in the upper mesosphere at low latitudes. On 29 June 2003, short-period ( $\sim 20 \mathrm{~min}$ ) gravity waves (GWs) were imaged in the MTM in the near-infrared $\mathrm{OH}$ and $\mathrm{O}_{2}$ airglow emissions for most of the night from 0700 to $1500 \mathrm{UT}$. The GWs were observed to disappear rapidly in the $\mathrm{O}_{2}$ data (peak altitude: $\sim 94 \mathrm{~km}$ ) around $1400 \mathrm{UT}$ but remained evident in the lower altitudes $\mathrm{OH}$ data $(\sim 87 \mathrm{~km})$ for a further $30 \mathrm{~min}$. Coincident background wind variations measured by the MWR suggest that the GW disappearance at the $\mathrm{O}_{2}$ layer was most probably caused by a critical level (CL) interaction. However, at the $\mathrm{OH}$ layer, the GW fading may also have been due to wave saturation and instabilities. During this period (1400-1500 UT), no significant change in $\mathrm{OH}$ and $\mathrm{O}_{2}$ rotational temperatures were measured by the MTM; however, the background winds centered on the airglow layers were observed to increase by $\sim 10 \mathrm{~m} / \mathrm{s}$. The background wind acceleration from the disappearing gravity waves estimated from the airglow observations was larger below the CL than at the CL, consistent with the wind variation observed by the MWR.

Citation: Ejiri, M. K., M. J. Taylor, T. Nakamura, and S. J. Franke (2009), Critical level interaction of a gravity wave with background winds driven by a large-scale wave perturbation, J. Geophys. Res., 114, D18117, doi:10.1029/2008JD011381.

\section{Introduction}

[2] Atmospheric gravity waves (GWs), generated by sources in the troposphere and the lower stratosphere, propagate play a central role in governing the dynamical coupling between the lower and upper atmospheric regions [Reid, 1986]. GWs propagate energy upward and eventually dissipate through one of several mechanisms, depositing their momentum and energy in the background wind and temperature fields. In particular, small-scale GWs with periods of $<1 \mathrm{~h}$ have been shown to be responsible for as much as $70 \%$ of the wave-induced transport that occurs in the mesosphere and lower thermosphere (MLT) region [Fritts and Vincent, 1987], although gravity waves with periods $>1 \mathrm{~h}$ are also important [Nakamura et al., 1993].

[3] Radar and lidar techniques have been used to investigate GW, frequencies, amplitudes, vertical structures, and flux's averaged over various time intervals [e.g., Reid, 1986; Nakamura et al., 1993; She et al., 1991; Hecht et al., 1993].

\footnotetext{
${ }^{1}$ Center for Atmospheric and Space Sciences and Physics Department, Utah State University, Logan, Utah, USA.

${ }^{2}$ Now at Research Institute for Sustainable Humanosphere, Kyoto University, Uji, Japan.

${ }^{3}$ Research Institute for Sustainable Humanosphere, Kyoto University, Uji, Japan.

${ }^{4}$ Department of Electrical and Computer Engineering, University of Illinois at Urbana-Champaign, Urbana, Illinois, USA.

Copyright 2009 by the American Geophysical Union. 0148-0227/09/2008JD011381
}

Horizontal scales and parameters of GWs have been estimated by multiradar observations [e.g., Meek and Manson, 1992; Gavrilov et al., 1995]. However, radar information on the horizontal dynamics of GWs has been limited. On the other hand, airglow imaging techniques have been used to determine the horizontal structures of GWs that modulate the airglow emission layers that reside in the MLT region and also to quantify their momentum flux $\left(F_{\mathrm{M}}\right)$ for vertically propagating waves [Swenson and Liu, 1998]. Previous statistical studies of GWs observed by airglow imagers have reported typical spatial and temporal scales of 5 to $60 \mathrm{~km}$ and 5 to $30 \mathrm{~min}$ for the horizontal wavelengths and observed periods, respectively [e.g., Wu and Killeen, 1996; Taylor et al., 1997; Walterscheid et al., 1999; Ejiri et al., 2003; Nakamura et al., 1999, 2001, 2003; Suzuki et al., 2004; Wrasse et al., 2006]. Recently, several attempts have been made to estimate the $F_{\mathrm{M}}$ carried by gravity waves seen in airglow images [Swenson and Liu, 1998; Gardner et al., 1999; Fritts et al., 2002; Hickey and Brown, 2002; Tang et al., 2002, 2005; Espy et al., 2004; Suzuki et al., 2007]. In particular, Yamada et al. [2001] reported a breaking GW event observed with an $\mathrm{OH}$ imager exhibiting very large intensity perturbations $\left(I^{\prime} / \overline{\mathrm{I}} \sim 55 \%\right)$. Fritts et al. [2002] estimated that this event had an extremely large $F_{\mathrm{M}}$ of $\sim 900 \mathrm{~m}^{2} / \mathrm{s}^{2}$ and produced a mean flow acceleration of $\sim 80 \mathrm{~m} / \mathrm{s}$ in less than an hour. In contrast, Hickey and Brown [2002] determined the altitude variation of $F_{\mathrm{M}}$ using ALOHA-93 GW parameters observed in $\mathrm{O}_{2}$ atmospheric band and OI $(557.7 \mathrm{~nm})$ combined with modeling. They 
analyzed four more typical GW events and found that only one had a maximum $F_{\mathrm{M}}>50 \mathrm{~m}^{2} / \mathrm{s}^{2}$. Indeed, most waves (over 90\%) evident in midlatitude airglow imagery carry relatively small amounts of $F_{\mathrm{M}}$ (less than $10 \mathrm{~m}^{2} / \mathrm{s}^{2}$ ) [Tang et al., 2005]. and large $F_{\mathrm{M}}$ events appear to relatively rare.

[4] Strong wind shears associated with the GWs may be large enough to create dynamical instabilities in the form of Kelvin-Helmholtz (KH) billows. Similarly, the background temperature gradient could be large enough to form a convective instability, or the wave may encounter a critical level at which the horizontal phase velocity relative to the ground equals the background wind velocity. Even in the absence of instabilities, GWs may be absorbed into the mean flow through viscous dissipation. Although features suggesting dynamical instabilities have long been known to exist in the mesosphere [e.g., Lloyd et al., 1973], only recently, with the advent of advanced numerical models, lidars, radars, and airglow imagers, have more definitive studies been possible. Many researchers have examined the structures formed when dynamical instabilities occur [e.g., Lloyd et al., 1973; Gossard and Hooke, 1975; Reid et al., 1987; Fritts et al., 1997]. In the simplest situation of a speed shear (no rotational shear), dynamical instability structures can form that are aligned parallel to the phase front of the GW and perpendicular to the direction of the shear. Several studies have also examined convective instabilities produced by breaking GWs. In particular, Fritts et al. [1997] used a three-dimensional numerical simulation to show that the phase fronts produced by a convective instability are aligned perpendicular to the breaking GW crests. Hecht et al. [1997, 2000] have described observations of such perpendicular wave-like structures in the $\mathrm{OH}$ emission at the same time when lidar observations of the temperature gradient (from 85 to $90 \mathrm{~km}$ ) indicated the presence of a super adiabatic lapse rate.

[5] The importance of critical levels (CL) in the dynamics of the atmosphere has been long recognized [e.g., Bretherton, 1966; Booker and Bretherton, 1967; Hazel, 1967; Hines, 1968; Breeding, 1971; Gossard and Hooke, 1975; Taylor et al., 1993; Huang et al., 1998; Gardner and Taylor, 1998]. In the simplest case, as the GW approaches a CL, its vertical wavelength decreases, coming close to zero at the CL, the point at which the wave can no longer propagate vertically. Subsequent wave dissipation at a CL can cause large accelerations of the mean flow. When a vertically propagating GW approaches a CL perturbations of horizontal wind associated with the GW (GW amplitude) increase significantly with altitude. The GW becomes saturated at an altitude where its amplitude becomes equal to its intrinsic phase speed. This altitude is called the saturation level (SL). Fritts [1984] has discussed the mean flow acceleration caused by GW dissipation between the saturation level and the critical level. For example, a model study by Hickey and Brown [2002] using a GW event measured during the ALOHA-93 campaign showed that the wave momentum flux $\left(F_{\mathrm{M}}\right)$ decreased rapidly with increasing height from $\sim 64 \mathrm{~m}^{2} / \mathrm{s}^{2}$ at $92 \mathrm{~km}$ to $0 \mathrm{~m}^{2} / \mathrm{s}^{2}$ at $94 \mathrm{~km}$ as a consequence of the critical level interaction. The expected mean flow acceleration associated with this $F_{\mathrm{M}}$ divergence reached a value of $200 \mathrm{~m} / \mathrm{s} / \mathrm{h}$ just below the critical level. Hecht et al. [2001] used medium-frequency (MF) radar to determine wind acceleration in association with small-scale features in airglow image data generated by a dynamical instability. They concluded that the acceleration event was due to a CL-GW interaction. Huang et al. [1998, 2002] observed a sudden and large mesospheric heating (peak temperature rise $\sim 40 \mathrm{~K}$ ) using $\mathrm{Na}$ wind/temperature lidar measurements during the ALOHA-93 campaign. They compared GWs observed by an airborne airglow imager [Swenson et al., 1995] with the lidar wind and temperature profiles [Tao and Gardner, 1995] and concluded that the temperature increase was caused by heating due to turbulence in the background medium resulting from shear instability induced by a CL-GW interaction. However, the evidence for this interaction was indirect in these studies.

[6] In this study, we present new observations of a shortperiod GW event observed in two MLT airglow emissions, together with background wind and temperature measurements recorded simultaneously over Maui, Hawaii, on 29 June 2003. A detailed investigation of these joint data sets demonstrates more directly that the GWs dissipated during a CL-GW interaction. We further suggest that a significant portion of the observed background wind field acceleration was caused by deposition of the gravity wave momentum flux at the CL and below.

\section{Instrumentation and Observations}

[7] The Maui-Mesosphere and Lower Thermosphere (MALT) program utilized an optical and radar instrumentation suite to investigate the dynamics of the low-latitude middle atmosphere in unprecedented detail. This program was a joint research initiative between the U.S. Air Force Office of Scientific Research (AFOSR) and the National Science Foundation (NSF), utilizing the Air Force Maui Optical Station (AMOS) facility at the summit of Haleakala Crater, Maui, Hawaii $\left(20.8^{\circ} \mathrm{N}, 156.2^{\circ} \mathrm{W}\right)$. As part of this program, the Utah State University Mesospheric Temperature Mapper (MTM) was operated at this site for a 5-year period (November 2001 to December 2006), providing twodimensional airglow intensity and rotational temperature measurements. From May 2002, these measurements were complemented by continuous observations of the MLT wind field $(\sim 80-100 \mathrm{~km})$ using the University of Illinois Meteor Wind Radar (MWR) located at Kihei, Maui, Hawaii $\left(20.8^{\circ} \mathrm{N}\right.$, $\left.156.4^{\circ} \mathrm{W}\right)$. Together these data have enabled detailed investigations of short-period gravity waves.

\subsection{Mesospheric Temperature Mapper}

[8] The MTM is a high-performance imaging system capable of observing wave-induced fluctuations in intensity and rotational temperatures for the $\mathrm{OH}(6,2)$ Meinel band and $\mathrm{O}_{2}(0,1)$ atmospheric band emissions. A large-format $\left(6.45 \mathrm{~cm}^{2}\right), 1024 \times 1024$ pixel CCD array is coupled to a telecentric lens system with a circular field of view of $90^{\circ}$. The high quantum efficiency and low noise characteristics of the CCD array provide precise measurements of $\mathrm{OH}$ and $\mathrm{O}_{2}$ emission intensity $(<0.5 \%$ in $1 \mathrm{~min})$ and derived rotational temperatures ( $<1-2 \mathrm{~K}$ in $3 \mathrm{~min})$ [e.g., Pendleton et al., 2000; Taylor et al., 2001].

[9] Sequential exposures were made using temperaturestabilized narrow-band $(\Delta \lambda \sim 1.2 \mathrm{~nm})$ filters centered at 840 and $846.5 \mathrm{~nm}$ for the $\mathrm{OH}(6,2)$ Meinel band $\left(\mathrm{P}_{1}(2)\right.$ and $\mathrm{P}_{1}(4)$, respectively) and 866 and $868 \mathrm{~nm}$ for the $\mathrm{O}_{2}(0,1)$ atmospheric band, followed by a background sky measurement 

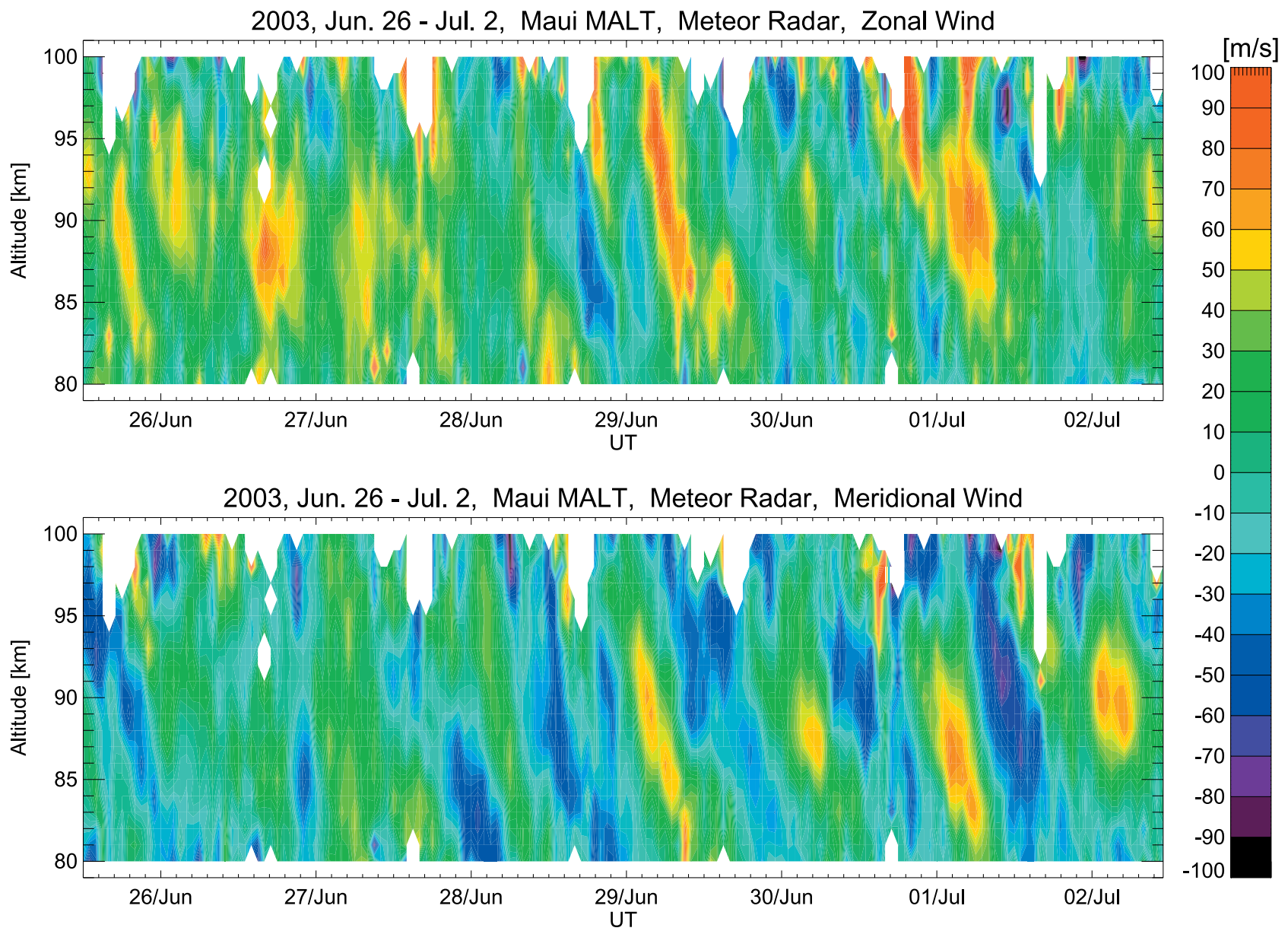

Figure 1. (top) Zonal and (bottom) meridional wind over Maui as measured by the MWR during a 7-day period (26 June to 2 July 2003).

at $857 \mathrm{~nm}$. The exposure time for each filter was $60 \mathrm{~s}$, resulting in a cycle time of $\sim 5.5 \mathrm{~min}$. Zenith rotational temperatures were computed separately for both emissions using the ratio method, as described by Meriwether [1984], and have been compared directly with simultaneous temperature measurements obtained by the University of Illinois wind-temperature lidar as part of the Maui-MALT program. Nocturnal temperature variability measured by these two different instrumental techniques showed good agreement with average root-mean squares of temperature differences of approximately 6 to $7 \mathrm{~K}$ at the assumed emission altitudes of $87 \mathrm{~km}(\mathrm{OH})$ and $94 \mathrm{~km}\left(\mathrm{O}_{2}\right)$ [Zhao et al., 2005].

\subsection{Meteor Wind Radar}

[10] The University of Illinois MWR is a commercially available SKiYMET system operated at $40.92 \mathrm{MHz}$, and has been described in detail by Franke et al. [2005]. The algorithms used to compute the meteor trail position and Doppler shift have also been fully described by Hocking and Thayaparan [1997]. Wind velocities were estimated from the trail positions and Doppler shifts using a weighted least squares fit to an assumed constant wind vector composed of horizontal eastward and northward components (with negligible vertical wind component). The height resolution of the estimated winds was $4 \mathrm{~km}$. Processed zonal and meridional wind profiles are readily available at $1-\mathrm{km}$ intervals with a time resolution of 30 min throughout the 80 to $100 \mathrm{~km}$ range.

[11] Figure 1 shows an example of the zonal and meridional wind fields over Maui measured by the MWR during a 7-day period (26 June to 2 July 2003), plotted with height and time resolutions of $4 \mathrm{~km}$ and $1 \mathrm{~h}$, respectively. The wind field during this time was dominated by an $\sim 24$-h-period oscillation with a clear downward phase progression of $\sim 1 \mathrm{~km} / \mathrm{h}$, most probably due to the diurnal tide. On 29 June, this tidal signature was particularly strong in both the zonal and meridional wind components. A critical level event for a short-period $(\sim 20 \mathrm{~min})$ gravity wave was observed on this night, as detailed in sections 3 and 4.

\section{Analysis}

\subsection{Image Processing and Wave Parameter Analysis}

[12] To investigate GWs, the MTM images were processed using the following procedure. First, the images were calibrated using the star field and then bright pixels due to stars (or cosmic rays) were replaced by average values of the surrounding pixels. Each image was then flat-fielded using the nightly average intensity. $\mathrm{OH}\left(\mathrm{O}_{2}\right)$ rotational temperatures were calculated from the sequential $\mathrm{P}_{1}(2)$, $\mathrm{P}_{1}(4)(866 \mathrm{~nm}, 868 \mathrm{~nm})$ and background image, and then their corresponding band intensities were determined. The 

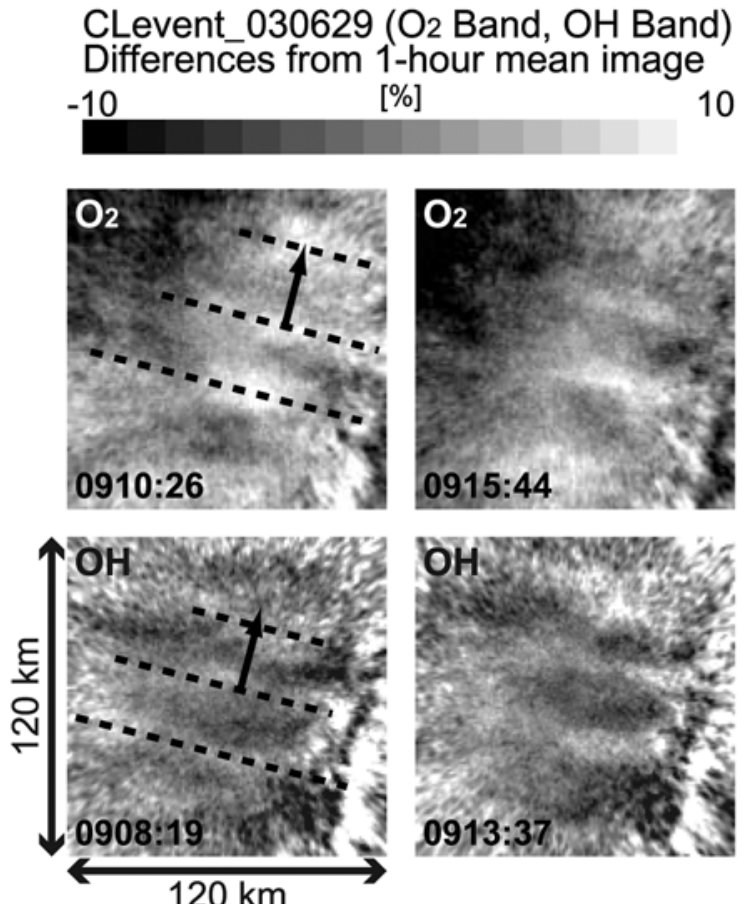

Figure 2. Short-period ( $\sim 20-\mathrm{min})$ GWs obtained in the processed (bottom) $\mathrm{OH}$ band and (top) $\mathrm{O}_{2}$ band intensity images around 0910 UT on 29 June 2003. These images are shown as differences (in percent) from a 1-h average image. Each image represents a $120-\mathrm{km}$-square area at the airglow altitudes (OH: $\left.87 \mathrm{~km}, \mathrm{O}_{2}: 94 \mathrm{~km}\right)$. Upward and to the right are north and east, respectively. The GW wavefront and horizontal propagation direction are marked with a dashed line and arrow, respectively.

processed images were then transformed into geographical coordinates and for this study plotted on a linear scale of 120 by $120 \mathrm{~km}$. The mapped data were then analyzed to determine the horizontal parameters of observed GWs using well-developed three-dimensional fast Fourier transform (FFT) [e.g., Garcia et al., 1997; Coble et al., 1998], and their observed phase speeds were obtained by comparing wavefront positions using a time sequence of mapped images.

\subsection{Momentum Flux}

[13] Swenson and Liu [1998] developed a method for estimating momentum flux $\left(F_{\mathrm{M}}\right)$ associated with a freely propagating gravity wave using its perturbation amplitude $\left(I^{\prime} / \overline{\mathrm{I}}\right)$, observed in the $\mathrm{OH}$ emission and its intrinsic wave parameter measurements (i.e., as measured in a reference frame moving with the background wind). Their formulation was derived under the assumption that the GW horizontal wavelength $\left(\lambda_{h}\right)$ is much larger than its vertical wavelength $\left(\lambda_{z}\right)$ in the MLT region. Owing to the finite depth of the $\mathrm{OH}$ and $\mathrm{O}_{2}$ emission layers (full width at half maximum (FWHM) of typically $8-10 \mathrm{~km}$ ), only gravity waves with $\lambda_{\mathrm{z}}$ significantly greater than the layer depth will be readily observed in the image data. Our estimates of $\lambda_{z}$ associated with shortperiod GWs indicate values comparable to their observed horizontal wavelengths (typically $>20 \mathrm{~km}$ ). We have there- fore revised the formula developed by Swenson and Liu [1998] under the assumption of $\lambda_{z} \sim \lambda_{h}$. The vertical group velocity $\left(V_{g z}\right)$ can then be described as follows [Vincent, 1984]:

$$
V_{\mathrm{gz}}=-\frac{m}{\left(m^{2}+k^{2}\right)} \frac{\omega^{2}-f^{2}}{\omega^{2}},
$$

where $\omega$ is the intrinsic frequency, $f$ is the inertial frequency, and $k\left(=2 \pi / \lambda_{h}\right)$ and $m\left(=2 \pi / \lambda_{z}\right)$ are the horizontal and vertical wave numbers, respectively. We then obtain a relationship between momentum flux, $F_{\mathrm{M}}$, and airglow intensity perturbation, $I^{\prime}$,

$$
F_{\mathrm{M}}=\frac{m k}{\left(m^{2}+k^{2}\right)} \frac{g^{2}}{N^{2}(\mathrm{CF})^{2}}\left(\frac{I^{\prime}}{\bar{I}}\right)^{2},
$$

where $N$ and $g$ are the Brunt-Väisälä frequency (typically $=$ $\left.2.0 \times 10^{-2} \mathrm{rad} / \mathrm{s}\right)$ and gravity acceleration $\left(=9.5 \mathrm{~m} / \mathrm{s}^{2}\right)$, respectively. $\mathrm{CF}$ is the cancellation factor relating the airglow intensity to the wave-perturbed atmospheric temperature and the observed intensity perturbation of the GW to its vertical wavelength [Swenson and Liu, 1998; Vargas et al., 2007]. To avoid strong cancellation effects within the airglow, CF is usually calculated for $\lambda_{z}>10 \mathrm{~km}$, which is the practical limit for observing short-period GW. Note that uncertainties in $\mathrm{CF}$ for $\lambda_{z}<20 \mathrm{~km}$ can lead to large uncertainties in $F_{\mathrm{M}}$, especially when $\lambda_{z}$ is close to $10 \mathrm{~km}(\mathrm{CF}<1)$. The vertical wave number $m$ is estimated for each wave event using the simplified GW dispersion relation, assuming that the atmosphere is an adiabatic incompressible fluid [Hines, 1960],

$$
m^{2}=\frac{N^{2}}{(c-u)^{2}}-\frac{1}{4 H^{2}}-k^{2},
$$

where $H$ is a scale height (typically $\sim 6 \mathrm{~km}$ ), $c$ is the observed GW horizontal phase speed, and $u$ is the background wind velocity projected in the direction of horizontal wave propagation. The background winds were height-averaged using a Gaussian weighting with a FWHM of $5.6 \mathrm{~km}(5.5 \mathrm{~km})$ for $\mathrm{OH}\left(\mathrm{O}_{2}\right)$ applied to the MWR data centered at $87 \pm 3 \mathrm{~km}$ $(94 \pm 3 \mathrm{~km})$ for $\mathrm{OH}\left(\mathrm{O}_{2}\right)$.

\section{Results}

[14] On 29 June 2003 the MTM was operated from 0700 to 1500 UT. Short-period ( $\sim 20 \mathrm{~min}$ ) GWs were observed in both the $\mathrm{OH}$ and $\mathrm{O}_{2}$ airglow layers almost continuously during this night from $\sim 0800$ to 1400 UT. Figure 2 shows the GWs evident in the processed $\mathrm{OH}$ band (Figure 2, bottom) and $\mathrm{O}_{2}$ band (Figure 2, top) intensity data at $\sim 0910$ UT. To highlight the wave structures the images are shown as differences (in percent) from a 1-h average image, plotted on a linear scale 120 by $120 \mathrm{~km}$. The top and right of each image are north and east, respectively. The GW wavefront and horizontal propagation direction are indicated by the dashed lines and arrows, respectively. In both the $\mathrm{O}_{2}$ and $\mathrm{OH}$ data the GWs propagated from SSW to NNE with similar horizontal wavelengths and phase velocities of $23.5 \mathrm{~km}$ and $23.5 \mathrm{~m} / \mathrm{s}$ for $\mathrm{O}_{2}$ and $24.5 \mathrm{~km}$ and $19.0 \mathrm{~m} / \mathrm{s}$ 

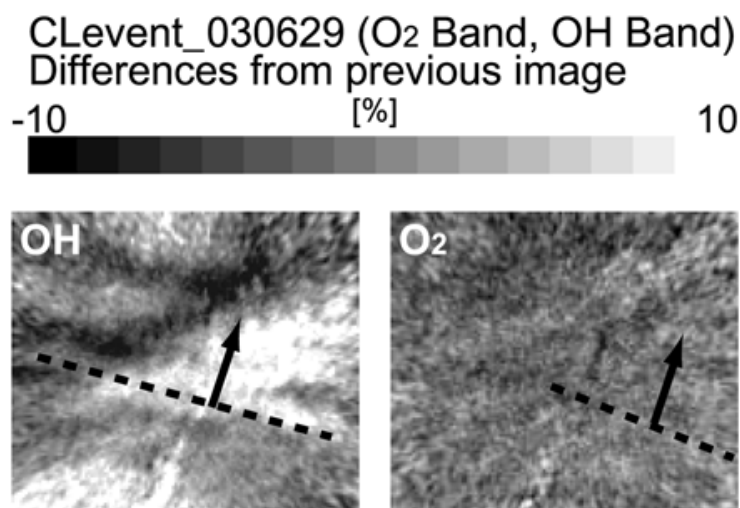

$11: 33 ; 15$
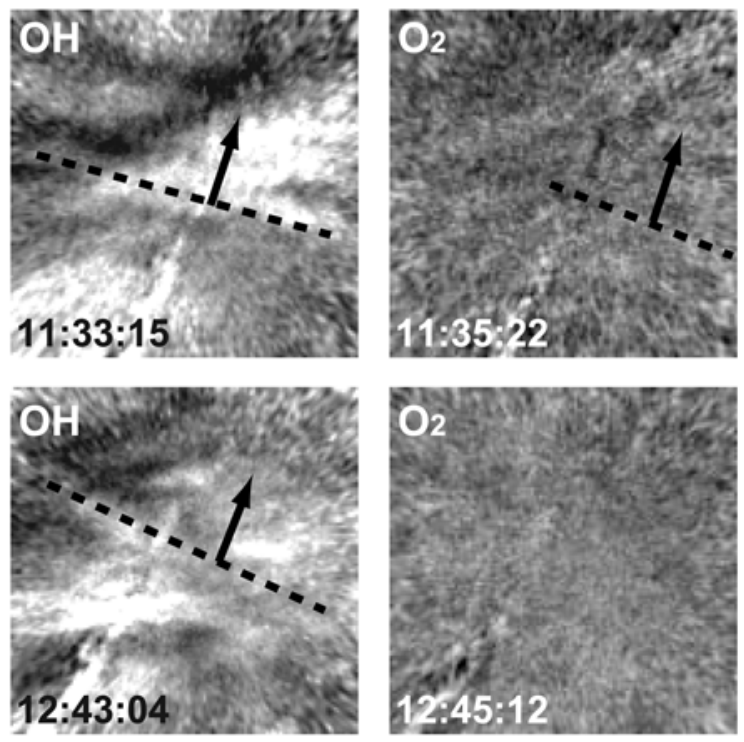

Figure 3. Typical GW structure observed in the (left) $\mathrm{OH}$ and (right) $\mathrm{O}_{2}$ images at (top) 1100 UT and (bottom) 1200 UT on 29 June 2003. These images are shown as differences (in percent) from a 1-h average image. The GW wavefront and horizontal propagation direction are marked with a dashed line and arrow, respectively. The GWs in $\mathrm{OH}$ images are clearly seen at both 1100 and 1200 UT, while the GW structures in $\mathrm{O}_{2}$ images are unclear at $1100 \mathrm{UT}$ and absent at $1200 \mathrm{UT}$.

for $\mathrm{OH}$, respectively. This wave pattern was evident in both emission layers for over $7 \mathrm{~h}$, except for 1100-1300 UT in $\mathrm{O}_{2}$.

[15] The GWs in the $\mathrm{O}_{2}$ data were observed continuously from 0800 to $1100 \mathrm{UT}$, after which time the wave structure grew faint and the horizontal parameters could no longer be defined (as shown in Figure 3, top right). No $\mathrm{O}_{2}$ wave structure was recognized after $\sim 1200$ UT (Figure 3, bottom right). However, this event reappeared around 1300 UT and was evident for a further $\sim 1 \mathrm{~h}$ before fading rapidly around 1400 UT, as shown in the image time sequence of Figure 4. In particular, the GW (delineated by the dashed lines) was still visible at 1401 UT (Figure 4, 14:01:21 image) but had disappeared by 1406 UT (Figure 4, 14:12:59 image). Comparison with the $\mathrm{OH}$ data shows that this $\mathrm{GW}$ event was observed continuously from 0700 to 1430 UT (including the period 1100-1300 UT, when the $\mathrm{O}_{2}$ wave structure had faded), thereafter it also disappeared. This is shown in Figure 5, where the GW crests (dashed lines) can be seen clearly at 1416 UT but by $\sim 1430$ UT the pattern had faded and the horizontal wavelength had decreased. The GW continued to fade and disappeared around 1445 UT.

\section{Discussion}

[16] The GWs disappeared first in the $\mathrm{O}_{2}$ image data, and then in the $\mathrm{OH}$ image data $30 \mathrm{~min}$ later, as presented in Figures 3, 4,
$\mathrm{O}_{2}$ Band
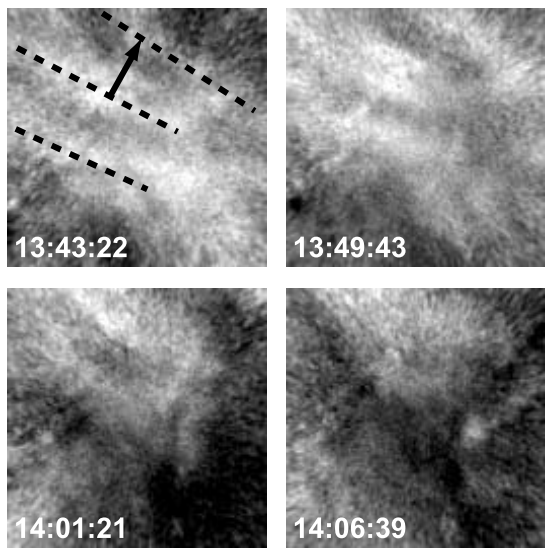

[\%]

15

Figure 4. The disappearance of GWs from the $\mathrm{O}_{2}$ images around 1400 UT. These images are shown as differences (in percent) from a 1-h average image with a time interval of $\sim 6$ min. In the 13:43:22 image the GW wavefront and horizontal propagation direction are marked with a dashed line and arrow, respectively. The GW can be seen by 1401 UT (14:01:21 image) but disappears at 1406 UT (14:06:39 image).

and 5. The $\mathrm{GW}$ in the $\mathrm{O}_{2}$ data disappeared immediately after 1401 UT (Figure 4). The $\mathrm{GW}$ in the $\mathrm{OH}$ data first grew faint and then disappeared (Figure 5). It is notable that the wavelength became shorter (similar to an instability event) at $\sim 1430$ UT and faded after 1439 UT. To investigate the disappearances, temporal variations in their propagation parameters and background winds have been analyzed in detail.

[17] Table 1 summarizes the horizontal parameters of the GW for each emission as measured at hourly intervals from 0700 to $1400 \mathrm{UT}$. The temporal variations in the

\section{OH Band}
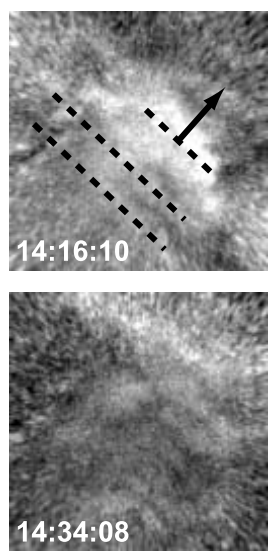

$-15$
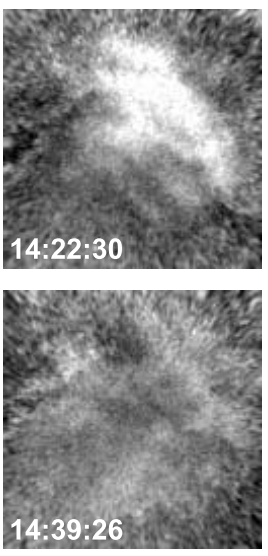

[\%]
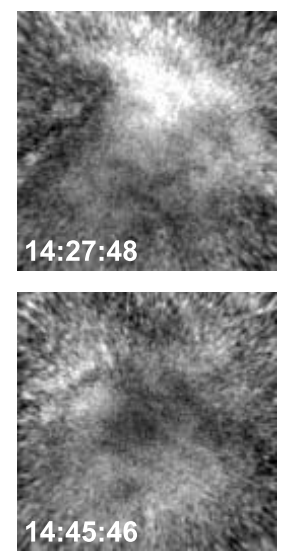

Figure 5. The image format follows Figure 4 for the $\mathrm{OH}$ images around $1430 \mathrm{UT}$. The GW can be seen clearly by 1422 UT (14:22:30 image). The wavelength became shorter at $\sim 1430$ (14:27:48 and 14:34:08 images). The GW then fades (14:39:26 image) and disappears after 1445 UT (14:45:46 image). 

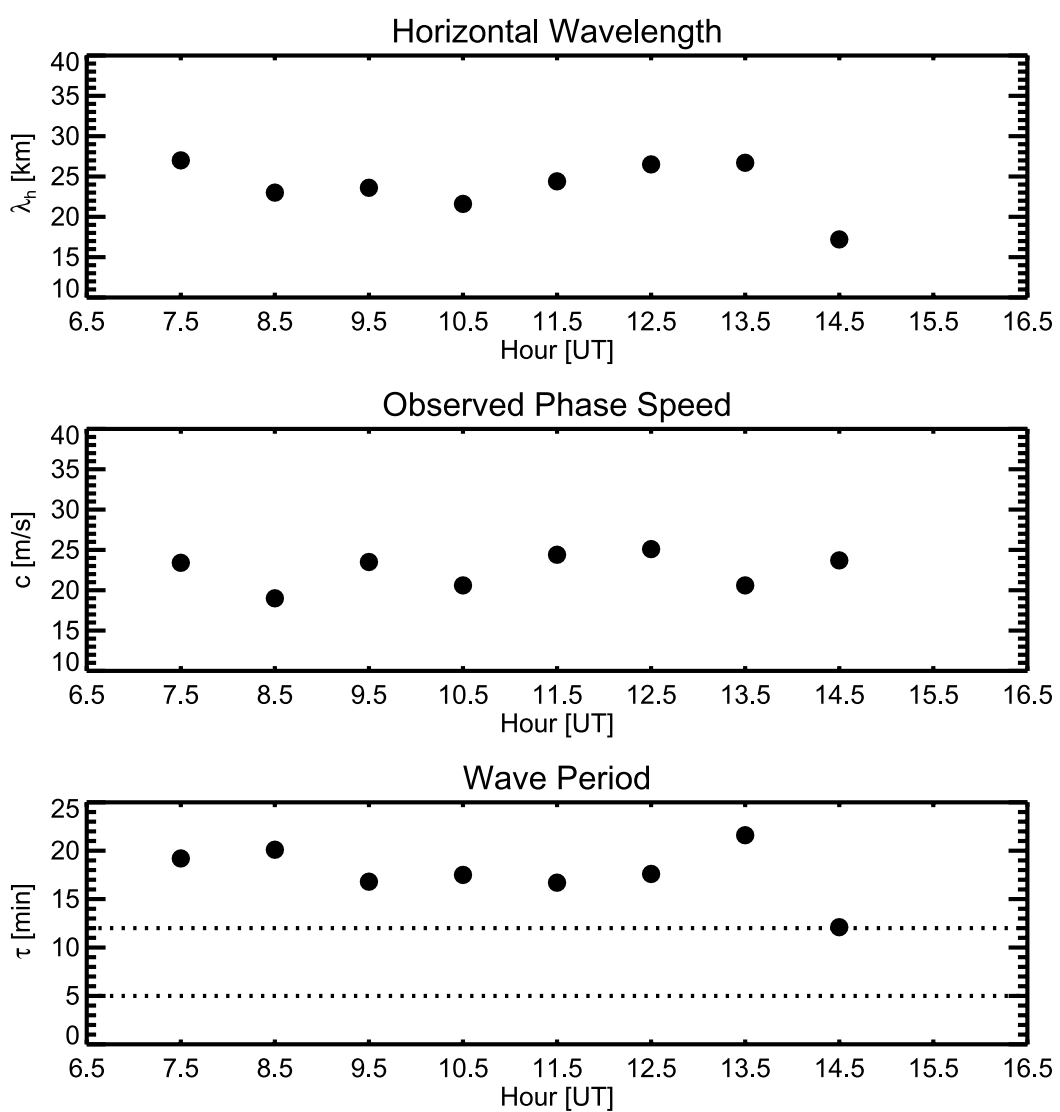

Figure 6. GW propagation parameter temporal variations obtained in the $\mathrm{OH}$ images: (top) horizontal wavelengths ( $\lambda_{h}$, standard deviation error: $1-1.5 \mathrm{~km}$ ), (middle) horizontal phase speeds ( $c$, standard deviation error: $0.5-1.5 \mathrm{~m} / \mathrm{s}$ ), and (bottom) observed periods ( $\tau$, standard deviation error: $0.5-1.5 \mathrm{~min}$ ). In the bottom plot, two dotted lines show 5-min and 12-min lines as a typical Brunt-Väisälä period (lower line) and twice the observation sequence (upper line), respectively.

$\mathrm{OH}$ parameters: horizontal wavelength $\left(\lambda_{h}\right.$, Figure 6 , top), observed horizontal phase velocity ( $c$, Figure 6 , middle), and observed wave period ( $\tau$, Figure 6 , bottom) are shown. The two dotted lines in Figure 6 (bottom) indicate the BruntVäisälä period, $\sim 5 \mathrm{~min}$, and the Nyquist period $\sim 12 \mathrm{~min}$. These wave parameters were almost constant during the night up until $1430 \mathrm{UT}$ with standard deviations for $\lambda_{h}, c$, and $\tau$ of only $2 \mathrm{~km}, 2 \mathrm{~m} / \mathrm{s}$, and $2 \mathrm{~min}$, respectively. The $\lambda_{h}$ and $\tau$ at 1430 UT were significantly smaller than those before 1330 UT because the wavelength became shorter at $\sim 1430$ UT.

[18] Figure 7 (top) shows vectors representing the speed and direction of the GW imaged by the MTM in the $\mathrm{O}_{2}$ emission during the period from 0600 to 1600 UT on 29 June 2003. No arrow indicates that the GWs were absent (or insufficiently clear to determine the wave propagation parameters) from the image data. Corresponding background wind vectors at the nominal $\mathrm{O}_{2}$ emission altitude are also shown. The background winds were averaged with a Gaussian weighting in altitude with a FWHM of $5.5 \mathrm{~km}$ using the MWR wind data centered at $94 \pm 3 \mathrm{~km}$ for $\mathrm{O}_{2}$ data. Figure 7 (bottom) plots the corresponding wave and wind measurements for the $\mathrm{OH}$ data using a Gaussian weighting for the wind data of $5.6 \mathrm{~km}$ (FWHM) centered at $87 \pm 3 \mathrm{~km}$. The $\mathrm{GW}$ signatures in both the $\mathrm{OH}$ and $\mathrm{O}_{2}$ layers were mainly directed toward the NNE throughout the night with speeds of approximately 19 to $28.5 \mathrm{~m} / \mathrm{s}$. In contrast, the direction and magnitude of the background wind field varied significantly during the night at both the $\mathrm{OH}$ and $\mathrm{O}_{2}$ layers. The meridional components of background winds changed from south to north around 1000 to $1100 \mathrm{UT}$ at the $\mathrm{O}_{2}$ layer and 1300 to $1400 \mathrm{UT}$ at the $\mathrm{OH}$ layer. Zonal components of background wind increased eastward after $1400 \mathrm{UT}$ at the $\mathrm{O}_{2}$ layer and after $1100 \mathrm{UT}$ at the $\mathrm{OH}$ layer. As a result, the background wind directions approached the GW propagation directions creating potential critical level (CL) conditions.

Table 1. Typical Values of GW Horizontal Propagation Parameters Observed at Each Hour ${ }^{\mathrm{a}}$

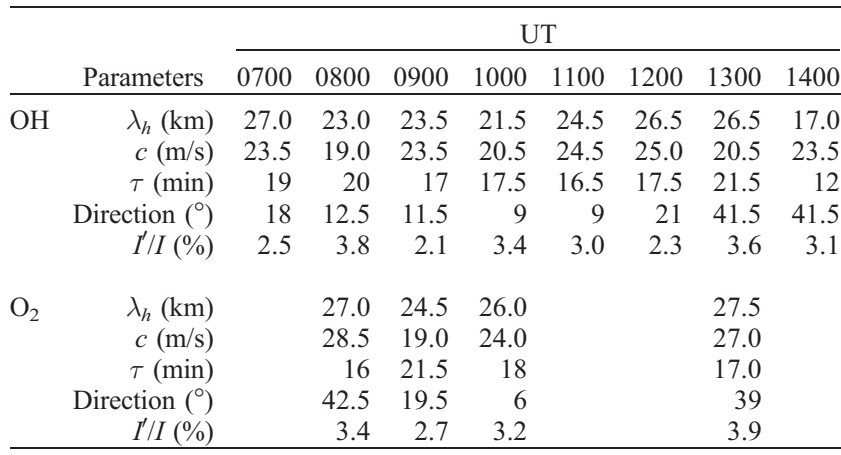

${ }^{\mathrm{a}}$ Error of $\lambda_{h}: \pm 1-1.5 \mathrm{~km}$; error of $c: \pm 0.51 .5 \mathrm{~m} / \mathrm{s}$; error of $\tau: \pm 0.5-$ $1.5 \mathrm{~min}$; error of direction: $\pm 1.5-2.5$ degree; and error of $I^{\prime} / I: \pm 0.3-0.65 \%$. 

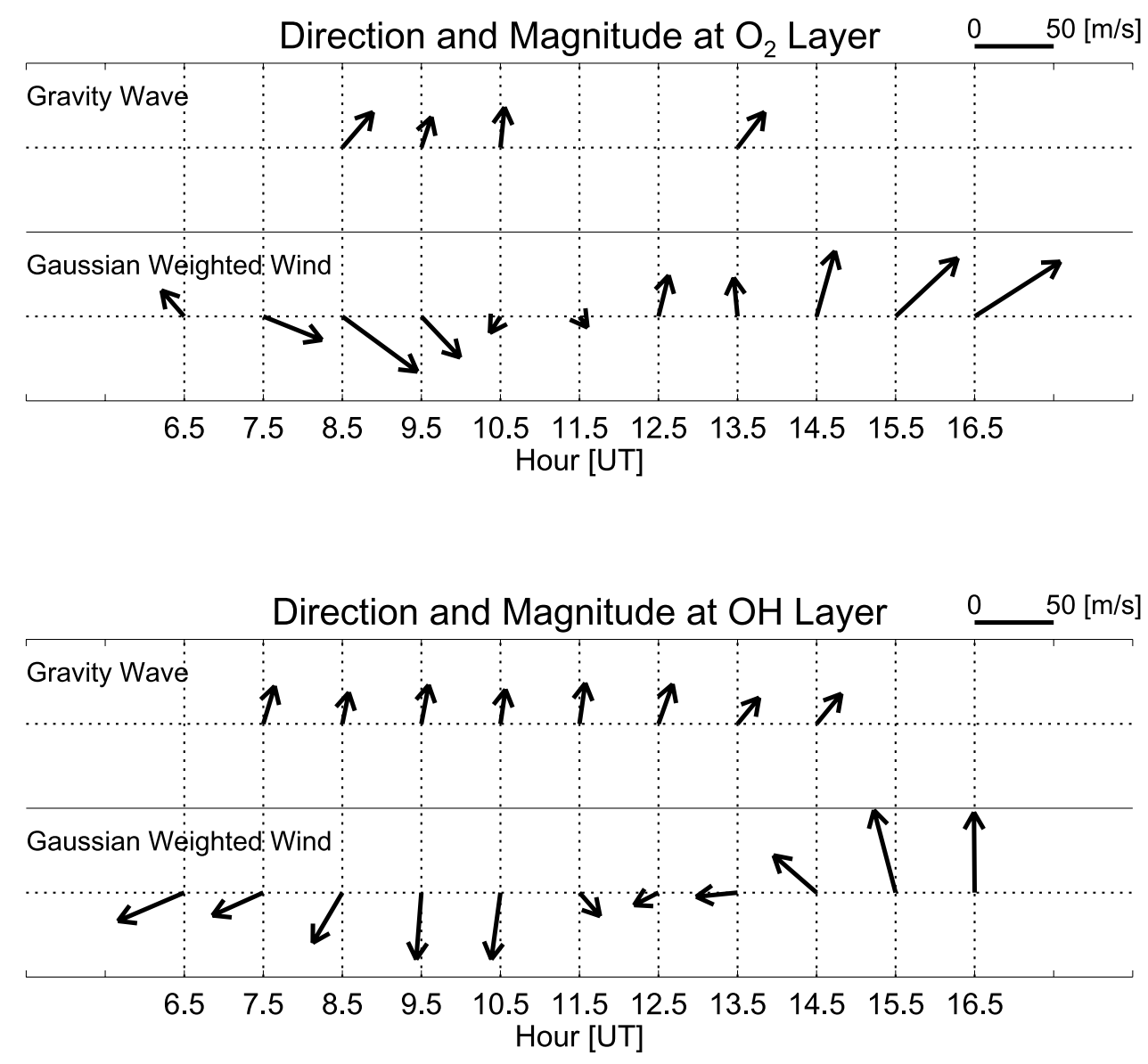

Figure 7. Arrows represent GW propagation hourly vectors (direction and speed) observed by the MTM and background wind measured by the MWR for 0600 to $1600 \mathrm{UT}$ in the (bottom) $\mathrm{OH}$ and (top) $\mathrm{O}_{2}$ layers on 29 June 2003. Vertical (horizontal) dotted lines mark the $0 \mathrm{~m} / \mathrm{s}$ axis of zonal (meridional) winds. Up (right) is north (east). The vertical dotted line intervals and horizontal dotted and solid line intervals correspond to $50 \mathrm{~m} / \mathrm{s}$. No arrow is shown when GWs were absent in eight sequential images over $1 \mathrm{~h}$.

[19] Temporal variations of the projected background wind (in the horizontal GW propagation direction) every $30 \mathrm{~min}$ for the $\mathrm{O}_{2}$ (Figure 8, top) and $\mathrm{OH}$ (Figure 8, bottom) layers are shown. The projected background wind data are shown as black dots and by open circles when the GWs were absent. Gray dots depict when GWs were difficult to see in which case the propagation parameters could not easily be analyzed and have been estimated (see Figure 8 caption for more details). It is evident that the projected background wind at the $\mathrm{O}_{2}$ layer nearly equaled the GW horizontal phase speed around $1400 \mathrm{UT}$, suggesting that a CL was generated. The projected background winds at the $\mathrm{OH}$ layer at $1430 \mathrm{UT}$ and 1500 UT remained lower than the GW horizontal phase speed. The derived intrinsic phase speeds and vertical wavelengths of the GWs measured in the $\mathrm{OH}$ data are plotted in Figure 9 (top and middle) at 30-min intervals. The intrinsic phase speeds decreased with time from $63 \mathrm{~m} / \mathrm{s}$ at 0930 UT to $25 \mathrm{~m} / \mathrm{s}$ at $1430 \mathrm{UT}$. The vertical wavelengths also decreased with time, falling below the typical width of the $\mathrm{OH}$ layer $(\sim 10 \mathrm{~km})$ around $1430 \mathrm{UT}$, indicating that the GW approached a CL, although the GW had not reached the CL when it disappeared.

[20] The momentum flux $\left(F_{\mathrm{M}}\right)$ of the $\mathrm{GW}$ evident in the $\mathrm{OH}$ data were calculated every $30 \mathrm{~min}$ and are also shown in
Figure 9 (bottom). For the first $\sim 4.5 \mathrm{~h}$ the $F_{\mathrm{M}} \mathrm{s}$ were relatively low around $5 \mathrm{~m}^{2} / \mathrm{s}^{2}$, but after $\sim 1130$ UT they became significantly larger (with high uncertainties) and more variable. This sudden change (increase) in $F_{\mathrm{M}}$ was probably due to a decrease in the vertical group velocity of the wave associated with the marked decrease in its vertical wavelength $\left(\lambda_{z}\right)$. The average values of all the calculated $F_{\mathrm{M}} \mathrm{s}$ are $13 \mathrm{~m}^{2} / \mathrm{s}^{2}$ for the $\mathrm{OH}$ data and $21 \mathrm{~m}^{2} / \mathrm{s}^{2}$ for the $\mathrm{O}_{2}$ data (not shown). The intrinsic phase speed $(|c-u|)$ represents an upper limit on the perturbation amplitude of horizontal velocity based on a convective instability threshold, $\left|u^{\prime}\right|_{\max } \sim|c-u|[$ Fritts et al., 2002]. The $\left|u^{\prime}\right|_{\max }$ is GW saturation amplitude, and an altitude at which the GW horizontal perturbation becomes equal to $\left|u^{\prime}\right|_{\max }$ is the saturation level (SL). The $\left|u^{\prime}\right|_{\text {max }}$ can be estimated using momentum flux $\left(F_{\mathrm{M}}=\left(2\left|u^{\prime}\right|\left|w^{\prime}\right|\right)^{-1}\right)$ and the continuity equation, $k\left|u^{\prime}\right|=-m\left|w^{\prime}\right|$, assuming that $F_{\mathrm{M}}$ did not vary with altitude [Fritts, 1984].

[21] Figure 10 shows vertical profiles of the background wind and GW parameters $\left(c-u\right.$ and $\left.\left|u^{\prime}\right|\right)$ between 1345 and $1500 \mathrm{UT}$, around the time of the GW disappearances in the $\mathrm{O}_{2}$ (Figures 10a and 10b) and $\mathrm{OH}$ (Figures 10c-10e) data. Each plot contains four profiles: $(c-u)$ (black solid thick line) and $\left|u^{\prime}\right|$ (black solid thin line) for the GWs, projected wind ( $u$, gray broken line), and its increase in time $(\delta u$, 

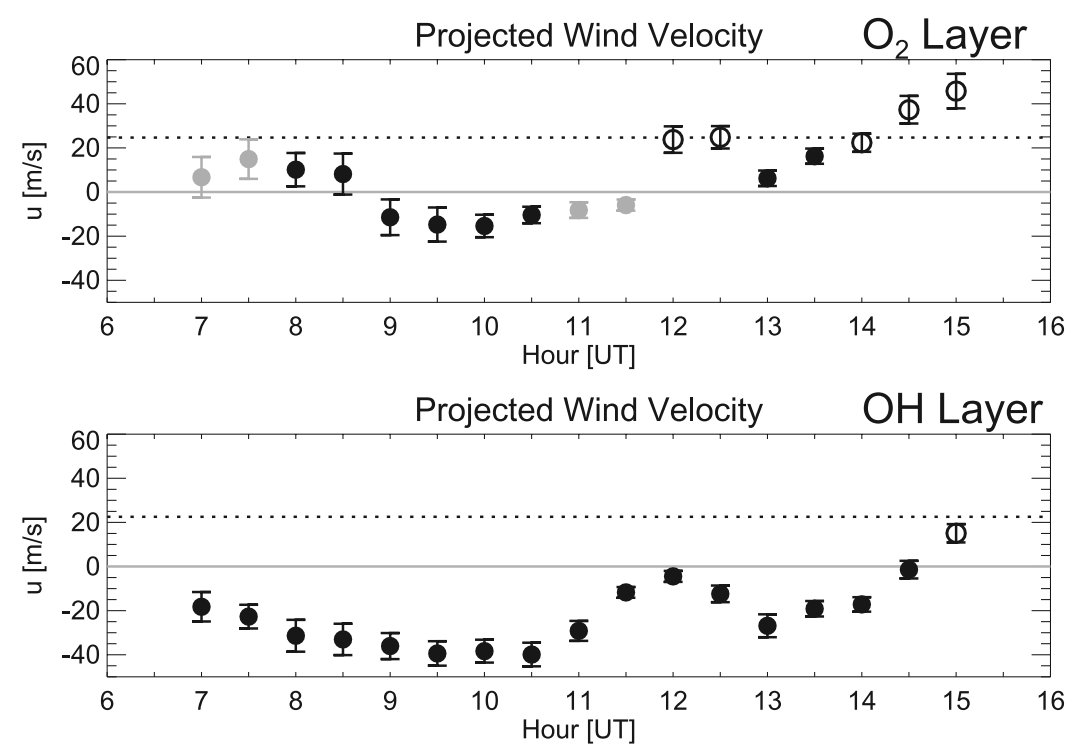

Figure 8. Projected wind temporal variations every $30 \mathrm{~min}$ at the (top) $\mathrm{O}_{2}$ and (bottom) $\mathrm{OH}$ altitudes. Projected winds are shown as black dots, gray dots (when GWs were difficult to see, so that the propagation parameters could not be analyzed), and circles (when GWs were absent). The projected winds shown as gray dots and circles were calculated using the propagation directions of GWs observed at the previous UT. Those before $0800 \mathrm{UT}$ for $\mathrm{O}_{2}$ were calculated using the direction of GW observed at $0800 \mathrm{UT}$. Standard deviations of each value are shown as vertical error bars. Dotted lines show the nightly average of observed phase speeds.
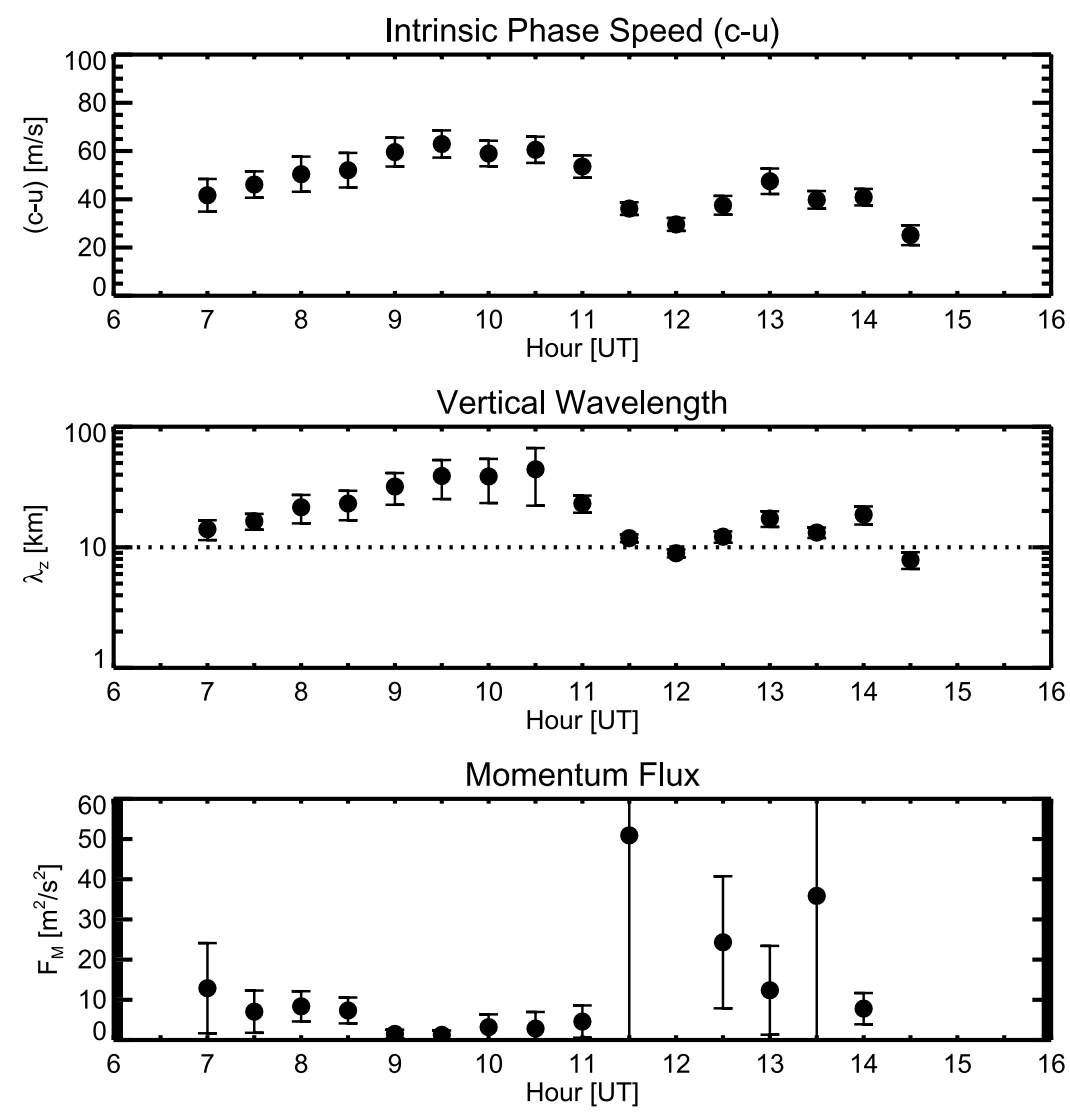

Figure 9. Temporal variations in the GW propagation parameters obtained at the $\mathrm{OH}$ layer: (top) horizontal intrinsic phase speeds $(c-u)$, (middle) vertical wavelengths $\left(\lambda_{z}\right)$, and (bottom) momentum flux $\left(F_{\mathrm{M}}\right)$. Vertical bars show standard deviation errors. 

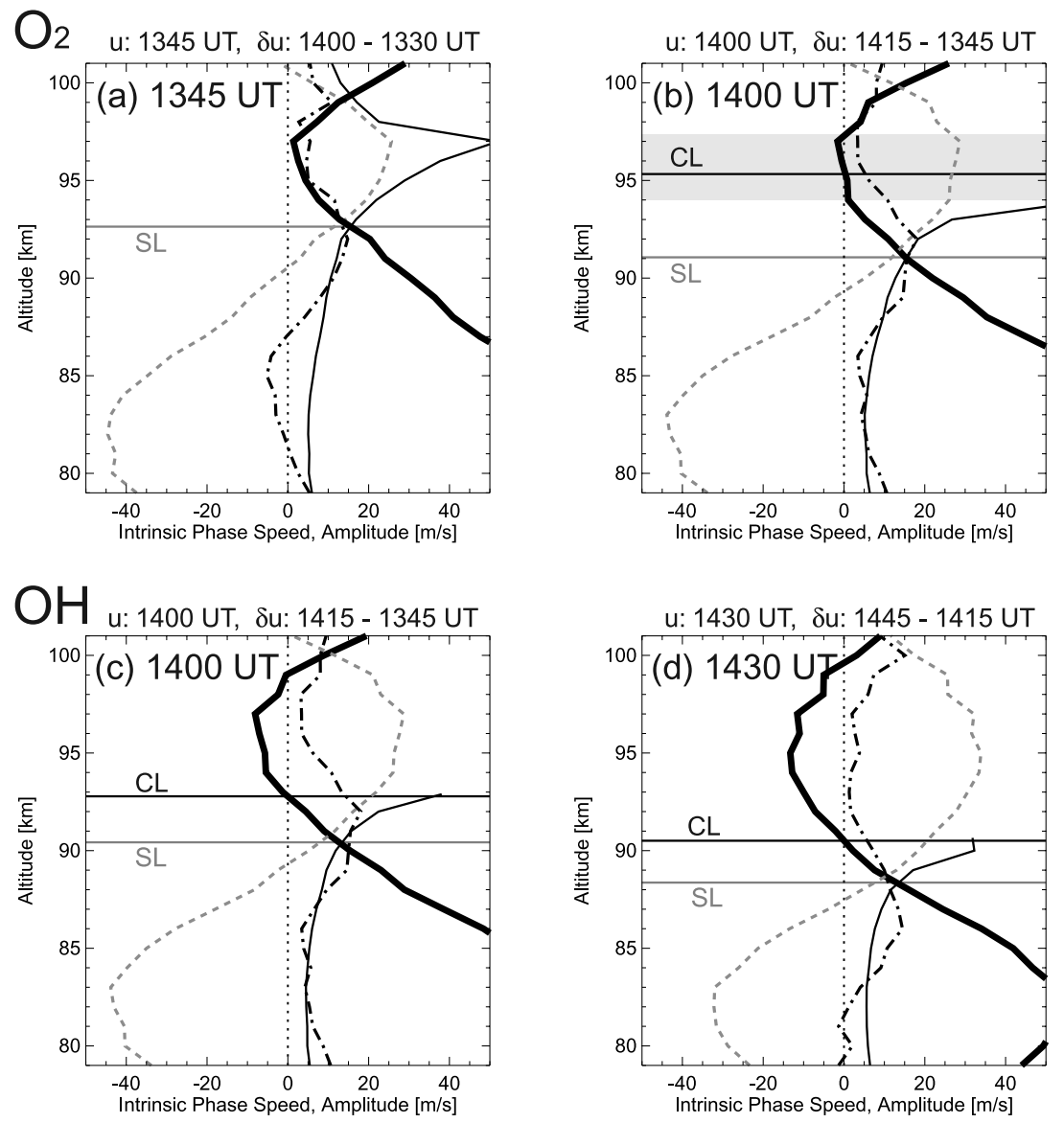
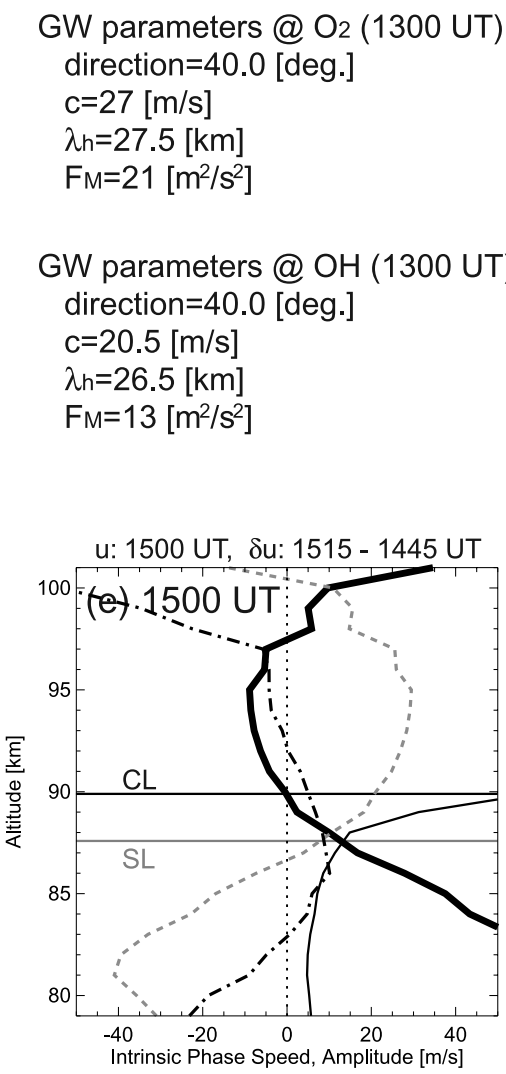

Figure 10. Relationships between critical levels (CL), saturation levels (SL), and background wind variations around the time of the $\mathrm{GW}$ disappearances in the $(\mathrm{a}, \mathrm{b}) \mathrm{O}_{2}$ and $(\mathrm{c}, \mathrm{d}$, and e) $\mathrm{OH}$ layers. Each plot has four profiles: $(c-u)$ (black solid thick line) and $\left|u^{\prime}\right|$ (black solid thin line) of the GWs, projected wind ( $u$, gray dashed line), and 30-min difference of $u$ ( $\delta u$, black dash-dotted line); for example, $\delta u_{(1400 \mathrm{UT})}=u_{(1415 \mathrm{UT})}-u_{(1345 \mathrm{UT})}$. The GW parameters observed at $1300 \mathrm{UT}$ used for the profile calculations appear at top right.

black dash-dotted line). For example, $\delta u$ at 1400 UT $\left(\delta u_{(1400 \mathrm{UT})}\right)$ was calculated as the 30 -min difference of $\mathrm{u}$, $\delta u_{(1400 \mathrm{UT})}=u_{(1415 \mathrm{UT})}-u_{(1345 \mathrm{UT})}$, where $u$ is the wind velocity at 30 -min time resolution. In each plot, $\left|u^{\prime}\right|$ and $(c-u)$ were calculated using the GW parameters at $1300 \mathrm{UT}$, for example, $\lambda_{h}=27.5 \mathrm{~km}$ (for the $\mathrm{O}_{2}$ ) and $26.5 \mathrm{~km}(\mathrm{OH})$, $c=27 \mathrm{~m} / \mathrm{s}\left(\mathrm{O}_{2}\right)$ and $20.5 \mathrm{~m} / \mathrm{s}(\mathrm{OH})$, and a propagation direction of 40 degrees.

[22] The GW observed in the $\mathrm{O}_{2}$ data disappeared immediately around 1400 UT, as shown in Figure 4. Figure 10a indicates an SL in the $\mathrm{O}_{2}$ data at $92.5 \mathrm{~km}$ around $1345 \mathrm{UT}$ (before the GW disappearance), but no CL. However, a CL was generated around 94 to $97.5 \mathrm{~km}$ at $1400 \mathrm{UT}$, as depicted in Figure 10b. The CL altitudes coincided well with the typical peak emission altitude of the $\mathrm{O}_{2}$ layer $(\sim 94 \mathrm{~km})$. In the $\mathrm{OH}$ data, the $\mathrm{GW}$ horizontal wavelength became shorter at $\sim 1430$ UT before fading out (as shown in Figure 5). Figures $10 \mathrm{c}-10 \mathrm{e}$ show that although a CL existed, it was located above $90 \mathrm{~km}$ (even at 1500 UT after the GW disappearance), which was higher than the typical altitude of the $\mathrm{OH}$ layer $(\sim 87 \mathrm{~km})$. These plots show that both the $\mathrm{CL}$ and SL moved down with a speed of $\sim 3 \mathrm{~km} / \mathrm{h}$. Impor- tantly, the SL was only $\sim 1 \mathrm{~km}$ above the $\mathrm{OH}$ peak altitude at 1430 UT. This suggests that the GW disappearance in the $\mathrm{OH}$ data was not caused by a CL-GW interaction, but instead occurred at or below the SL. With the CL and SL descent, the GW $\lambda_{z}$ decreased to less than $10 \mathrm{~km}$ at $1430 \mathrm{UT}$ and may have broken down at the $\mathrm{OH}$ layer owing to the short $\lambda_{z}$. It is also possible that the small $\lambda_{z}$ could have caused the fainter wave structure witnessed before the disappearance (due to cancellation effects within the $\mathrm{OH}$ layer). In contrast, the $\mathrm{GW}$ at the $\mathrm{O}_{2}$ layer probably propagated very close to the CL at 1400 UT, as shown in Figures 10b and 10c. Thus, a probable cause for the GW disappearance is mainly a CL-GW interaction during which the GW may have saturated and lost some of its $F_{\mathrm{M}}$ before disappearing. [23] To quantify the effects of the GW disappearances, $\delta u$ (30-min difference of background wind) profiles are also displayed in Figure 10. When the $\mathrm{GW}$ in the $\mathrm{O}_{2}$ data disappeared around 1400 UT (Figure 10b), $\delta u$ was 5 to $10 \mathrm{~m} / \mathrm{s}$ at the CL $(94-97.5 \mathrm{~km})$ and $15 \mathrm{~m} / \mathrm{s}$ around 89 to $93 \mathrm{~km}$ (below the CL). The 90.5- to $93-\mathrm{km}$ range marked a region between the SL and CL for the GW present in the $\mathrm{OH}$ data (Figure 10c). Impulses applied to background 
wind $(\Delta u)$ by the $F_{\mathrm{M}}$ of GWs were estimated using $\Delta u=$ $F_{\mathrm{M}} \Delta t / \Delta z$ [Fritts et al., 2002], where $\Delta t$ is the duration of wave breaking (saturation) and $\Delta z$ is the height extent of the breaking (saturation) event. The $\mathrm{GW}$ in the $\mathrm{O}_{2}$ data disappeared owing to a CL generated between 94 to $97.5 \mathrm{~km}$ $(\Delta z=3.5 \mathrm{~km})$ within $15 \mathrm{~min} ; \Delta t$ might be approximately $5 \mathrm{~min}$, as the GW disappeared between two images obtained in a 5-min interval (Figure 5). The average $F_{\mathrm{M}}$ of the GW before disappearance (before $1400 \mathrm{UT}$ ) was $21 \mathrm{~m}^{2} / \mathrm{s}^{2}$; therefore, the expected $\Delta u$ (by the GW disappearance) was $\sim 5.5 \mathrm{~m} / \mathrm{s}(\Delta t=15 \mathrm{~min})$ or less. As shown in Figure 10c, the SL and CL for the GW in the $\mathrm{OH}$ data occurred at 90.5 to $93 \mathrm{~km}$ (2.5 km width) at $1400 \mathrm{UT}$. The SL-CL region moved down with a speed of $\sim 3 \mathrm{~km} / \mathrm{h}$ and the average $F_{\mathrm{M}}$ of the GW before the break was $13 \mathrm{~m}^{2} / \mathrm{s}^{2}$. Therefore, $\Delta u$ (by the GW saturation) was estimated at $9.5 \mathrm{~m} / \mathrm{s}$ for $30 \min (\Delta z=2.5 \mathrm{~km}, \Delta t=50 \mathrm{~min})$. This value is somehow larger than the $\Delta u$ of $5.5 \mathrm{~m} / \mathrm{s}$ at the CL, but is qualitatively consistent with the $\delta u$ profile at $1400 \mathrm{UT}$. When the GW in the $\mathrm{OH}$ data disappeared around $1430 \mathrm{UT}, \delta u$ in Figure 10d increased over the 82 to $92 \mathrm{~km}$ range, with a maximum at $86 \mathrm{~km}$, possibly occurring as a result of wave breaking with concurrent reduction in horizontal wavelength in the $\mathrm{OH}$ data. Additionally, the upper part $(86-92 \mathrm{~km})$ of the acceleration region was wider than the bottom part $(82-$ $86 \mathrm{~km}$ ). This could have arisen from extra acceleration in the upper region from GW saturation between the SL and CL $(88-90.5 \mathrm{~km})$.

[24] The CL-GW interaction was probably triggered by a background wind change associated with the large-scale wave (period $>10 \mathrm{~h}$ ) observed on 29 June as shown in Figure 1. The perturbation may also have included vertically propagating semidiurnal and diurnal tides. However, the observed downward motion of the SL and CL $(\sim 3 \mathrm{~km} / \mathrm{h})$ was higher than the typical downward phase speed of the diurnal tide $(\sim 1 \mathrm{~km} / \mathrm{h})$. A single-mode diurnal tide cannot progress so quickly; we must take other effects into account, such as superposition of other waves (such as semidiurnal tides) and/or wind profile modification due to background wind acceleration by the breaking GW.

[25] Finally, the temporal variations in $\mathrm{O}_{2}$ and $\mathrm{OH}$ rotational temperatures observed by the MTM showed no significant change between 1400 and 1500 UT. This differs from the $\sim 40 \mathrm{~K}$ temperature increase reported by Huang et al. [1998, 2002] associated with a CL-GW interaction.

\section{Conclusions}

[26] On 29 June 2003, strong, diurnal oscillations were observed in both the zonal and meridional wind components over all measured altitudes $(\sim 80-100 \mathrm{~km})$ by the Meteor Wind Radar (MWR) sited at Kihei, Maui, Hawaii, most probably dominated by large-scale GWs (period $>10 \mathrm{~h}$ ), which also include propagating semidiurnal and diurnal tides. On the same night, a short-period ( $20-\mathrm{min})$ gravity wave (GW) was observed by a Mesospheric Temperature Mapper (MTM) located near the summit of Haleakala Crater, Maui, Hawaii. This GW was evident in both the $\mathrm{OH}$ and $\mathrm{O}_{2}$ airglow layers for much of the night but disappeared around 1430 and $1400 \mathrm{UT}$, in each airglow layer, respectively. Qualitative and quantitative investigations into the relation- ships between the observed GW dissipations and the increasing background wind field indicate the following:

[27] 1. The $\mathrm{GW}$ disappearance at the $\mathrm{O}_{2}$ layer was most probably caused by a critical level gravity wave (CL-GW) interaction at the CL that occurred rapidly (within $15 \mathrm{~min}$ ) around 1400 UT over the altitude ranges of $\sim 94$ to $97.5 \mathrm{~km}$.

[28] 2. The GW disappearance at the $\mathrm{OH}$ layer was apparently not due to a CL-GW interaction. On the basis of the slow descent of the saturation level (SL) and the small intrinsic phase speed $(c-u)$ at the $\mathrm{OH}$ layer altitude, the GW disappearance was probably caused by saturation and/or dissipations due to eddy diffusivity. The associated reduction in the vertical wavelength $\left(\lambda_{z}\right)<10 \mathrm{~km}$ could also have contributed to the GW disappearance.

[29] 3. The wave disappearance may have accelerated the background wind, resulting in an increase of $\sim 9.5 \mathrm{~m} / \mathrm{s}$ for 30 min; however, coincident measurements of the background temperature did not reveal any accompanying change owing to the wave disappearance.

[30] 4. The acceleration at the $\mathrm{CL}$ around the $\mathrm{O}_{2}$ layer was smaller than that below the CL because the $\mathrm{CL}$ descended rapidly and did not remain long there.

[31] Finally, it is important to note that dynamical and convective instabilities are the processes that alleviate the wave-breaking condition, but wave breaking at the CL and SL, as seen in this study, accelerated the background wind in the direction in which breaking occurs more easily, and at the lower altitudes, by creating a stronger wind shear. Wave breaking at the CL and SL is therefore an important process in long-period $(>10 \mathrm{~h})-$ short-period $(<1 \mathrm{~h}) \mathrm{GW}$ interactions. A major factor in clearing the wave breaking is considered to be the further phase progression of tides altering the wind shear direction.

[32] Acknowledgments. This research was conducted as a part of a joint Maui-MALT program between the Air Force Office of Scientific Research (AFOSR) and National Science Foundation (NSF) Coupling, Energetics and Dynamics of Atmospheric Regions (CEDAR) program. Financial support for the USU-MTM measurements was provided by NSF grant ATM-0003218, and support for Meteor Wind Radar observations and data analysis was provided by ATM-00-3182 and ATM-00-3198. M. K. Ejiri received support as a CEDAR postdoctoral fellow (NSF grant ATM0437589) and also as a Japan Society for the Promotion of Science postdoctoral fellow (JSPS grant 19-792).

\section{References}

Booker, J., and F. Bretherton (1967), The critical layer for internal gravity waves in a shear flow, J. Fluid Mech., 27, 513-539, doi:10.1017/ S0022112067000515.

Breeding, R. J. (1971), A non-linear investigation of critical levels for internal atmospheric gravity waves, J. Fluid Mech., 50, 545-563, doi: $10.1017 / \mathrm{S} 0022112071002751$.

Bretherton, F. P. (1966), The propagation of groups of internal gravity waves in a shear flow, Q. J. R. Meteorol. Soc., 92, 466-480, doi:10.1002/qj.49709239403.

Coble, M. R., G. C. Papen, and C. S. Gardner (1998), Computing twodimensional unambiguous horizontal wavenumber spectra from $\mathrm{OH}$ airglow images, IEEE Trans. Geosci. Remote Sens., 36(2), 368-382, doi:10.1109/36.662723.

Ejiri, M. K., K. Shiokawa, T. Ogawa, K. Igarashi, T. Nakamura, and T. Tsuda (2003), Statistical study of short-period gravity waves in $\mathrm{OH}$ and OI nightglow images at two separated sites, J. Geophys. Res., 108(D21), 4679, doi:10.1029/2002JD002795.

Espy, P. J., G. O. L. Jones, G. R. Swenson, J. Tang, and M. J. Taylor (2004), Seasonal variations of the gravity wave momentum flux in the Antarctic mesosphere and lower thermosphere, J. Geophys. Res., 109, D23109, doi:10.1029/2003JD004446.

Franke, S. J., X. Chu, A. Z. Liu, and W. K. Hocking (2005), Comparison of meteor radar and $\mathrm{Na}$ Doppler lidar measurements of winds in the meso- 
pause region above Maui, Hawaii, J. Geophys. Res., 110, D09S02, doi:10.1029/2003JD004486.

Fritts, D. C. (1984), Gravity wave saturation in the middle atmosphere: A review of theory and observations, Rev. Geophys., 22, 275-308, doi:10.1029/RG022i003p00275.

Fritts, D. C., and R. A. Vincent (1987), Mesospheric momentum flux studies at Adelaide, Australia: Observations and a gravity wave/tida interaction model, J. Atmos. Sci., 44, 605-619, doi:10.1175/1520-0469 (1987)044<0605:MMFSAA>2.0.CO;2.

Fritts, D. C., J. R. Isler, J. H. Hecht, R. L. Walterscheid, and Ø. Andreassen (1997), Wave breaking signatures in sodium densities and $\mathrm{OH}$ nightglow: 2. Simulation of wave and instability structures, J. Geophys. Res., 102(D6), 6669-6684, doi:10.1029/96JD01902.

Fritts, D. C., S. L. Vadas, and Y. Yamada (2002), An estimate of strong local body forcing and gravity wave radiation based on $\mathrm{OH}$ airglow and meteor radar observations, Geophys. Res. Lett., 29(10), 1429, doi:10.1029/2001GL013753.

Garcia, F. J., M. J. Taylor, and M. C. Kelley (1997), Two-dimensiona spectral analysis of mesospheric airglow image data, Appl. Opt., 36(29), 7374-7385, doi:10.1364/AO.36.007374.

Gardner, C., and M. J. Taylor (1998), Observational limits for lidar, radar, and airglow imager measurements of gravity wave parameters, J. Geophys. Res., 103(D6), 6427-6437, doi:10.1029/97JD03378.

Gardner, C. S., K. Gulati, Y. Zhao, and G. R. Swenson (1999), Measuring gravity wave momentum fluxes with airglow images, J. Geophys. Res. 104(D10), 11,903-11,915.

Gavrilov, N. M., et al. (1995), Climatological monthly characteristics of middle atmosphere gravity waves (10-min 10-h) during 1979-1993 at Saskatoon, Ann. Geophys., 13(3), 285-295.

Gossard, E. E., and W. H. Hooke (1975), Wave in the Atmosphere, Elsevier, New York.

Hazel, P. (1967), The effect of viscosity and heat conduction on internal gravity waves at a critical level, J. Fluid Mech., 30, 775-786, doi:10.1017/S0022112067001752.

Hecht, J. H., et al. (1993), Simultaneous nightglow and Na lidar observations at Arecibo during the AIDA-89 campaign, J. Atmos. Terr. Phys., 55, 409-423, doi:10.1016/0021-9169(93)90077-C

Hecht, J. H., R. L. Walterscheid, D. C. Fritts, J. R. Isler, D. C. Senft, C. S. Gardner, and S. J. Franke (1997), Wave breaking signatures in OH airglow and sodium densities and temperature: 1 . Airglow imaging, $\mathrm{Na}$ lidar, and MF radar observations, J. Geophys. Res., 102(D6), 6655-6668, doi:10.1029/96JD02619.

Hecht, J. H., C. Fricke-Begemann, R. L. Walterscheid, and J. Höffner (2000), Observations of the breakdown of an atmospheric gravity wave near the cold summer mesopause at $54^{\circ} \mathrm{N}$, Geophys. Res. Lett., 27(6), $879-882$

Hecht, J. H., R. L. Walterscheid, and R. A. Vincent (2001), Airglow observations of dynamical (windshear-induced) instabilities over Adelaide, Australia, associated with atmospheric gravity waves, J. Geophys. Res., 106(D22), 28,189-28,197, doi:10.1029/2001JD000419.

Hickey, M. P., and J. S. Brown (2002), A simulation study of space-based observations of gravity waves in the airglow using observed ALOHA-93 wave parameters, J. Geophys. Res., 107(A12), 1431, doi:10.1029/ 2001JA009225

Hines, C. O. (1960), Internal atmospheric gravity waves at ionospheric heights, Can. J. Phys., 38(11), 1441-1481.

Hines, C. O. (1968), Some consequences of gravity-wave critical layers in the upper atmosphere, J. Atmos. Terr. Phys., 30, 837-843.

Hocking, W. K., and T. Thayaparan (1997), Simultaneous and co-located observation of winds and tides by $\mathrm{MF}$ and meteor radars over London, Canada $\left(43^{\circ} \mathrm{N}, 81^{\circ} \mathrm{W}\right)$, during $1994-1996$, Radio Sci., 32(2), 833-865, doi:10.1029/96RS03467.

Huang, T. Y., H. Hur, T. F. Tuan, X. Li, E. M. Dewan, and R. H. Picard (1998), Sudden narrow temperature-inversion-layer formation in ALOHA-93 as a critical-layer-interaction phenomenon, J. Geophys. Res., 103(D6), 6323-6332, doi:10.1029/97JD03076.

Huang, T.-Y., M. P. Hickey, T.-F. Tuan, E. M. Dewan, and R. H. Picard (2002), Further investigations of a mesospheric inversion layer observed in the ALOHA-93 Campaign, J. Geophys. Res., 107(D19), 4408, doi:10.1029/2001JD001186.

Lindzen, R. S. (1981), Turbulence and stress owing to gravity wave and tidal breakdown, J. Geophys. Res., 86(C10), 9707-9714, doi:10.1029/ JC086iC10p09707.

Lloyd, K. H., C. H. Low, and R. A. Vincent (1973), Turbulence, billows, and gravity waves in a high shear region of the upper atmosphere, Planet. Space Sci., 21, 653-661, doi:10.1016/0032-0633(73)90076-7.

Meek, C. E., and A. H. Manson (1992), Angle-of-arrival oscillations in the mesosphere as seen by medium frequency (MF) radar, J. Atmos. Tern Phys., 54, 277-293, doi:10.1016/0021-9169(92)90008-9.
Meriwether, J. W. (1984), Ground based measurements of mesospheric temperatures by optical means, in Middle Atmosphere Program Handbook for $M A P$, vol. 13, edited by R. Vincent, pp. 1-18, NASA Goddard Space Flight Center, Greenbelt, Md.

Nakamura, T., T. Tsuda, M. Yamamoto, S. Fukao, and S. Kato (1993) Characteristics of gravity waves in the mesosphere observed with the MU radar: 1. Momentum flux, J. Geophys. Res., 98(D5), 8899-8910, doi:10.1029/92JD02978.

Nakamura, T., A. Higashikawa, T. Tsuda, and Y. Matsushita (1999), Seasonal variations of gravity wave structures in $\mathrm{OH}$ airglow with a CCD imager at Shigaraki, Earth Planets Space, 51, 897-906.

Nakamura, T., T. Tsuda, R. Maekawa, M. Tsutsumi, K. Shiokawa, and T. Ogawa (2001), Seasonal variation of gravity waves with various temporal and horizontal scales in the MLT region observed with radar and airglow imaging, Adv. Space Res., 27, 1737-1742, doi:10.1016/ S0273-1177(01)00310-6.

Nakamura, T., T. Aopno, T. Tsuda, A. G. Admiranto, E. Achmad, and Suranto (2003), Mesospheric gravity waves over a tropical convective region observed by $\mathrm{OH}$ airglow imaging in Indonesia, Geophys. Res. Lett., 30(17), 1882, doi:10.1029/2003GL017619.

Pendleton, W. R., Jr., M. J. Taylor, and L. C. Gardner (2000), Terdiurnal oscillations in $\mathrm{OH}$ Meinel rotational temperatures for fall conditions at northern midlatitude sites, Geophys. Res. Lett., 27(12), 1799-1802, doi:10.1029/2000GL003744

Reid, I. M. (1986), Gravity wave motions in the upper middle atmosphere (60-110 km), J. Atmos. Terr. Phys., 48, 1057-1072, doi:10.1016/00219169(86)90026-7.

Reid, I. M., R. Rüster, and G. Schmidt (1987), VHF radar observations of cat's-eye-like structures at mesospheric heights, Nature, 327, 43-45, doi: $10.1038 / 327043 \mathrm{a} 0$

She, C. Y., J. R. Yu, J. W. Huang, C. Nagasawa, and C. S. Gardner (1991), $\mathrm{Na}$ temperature lidar measurements of gravity wave perturbations of wind, density and temperature in the mesopause region, Geophys. Res. Lett., 18(7), 1329-1331, doi:10.1029/91GL01517.

Suzuki, S., K. Shiokawa, Y. Otsuka, T. Ogawa, and P. Wilkinson (2004), Statistical characteristics of gravity waves observed by an all-sky imager at Darwin, Australia, J. Geophys. Res., 109, D20S07, doi:10.1029/ 2003JD004336.

Suzuki, S., K. Shiokawa, Y. Otsuka, T. Ogawa, K. Nakamura, and T. Nakamura (2007), A concentric gravity wave structure in the mesospheric airglow images, J. Geophys. Res., 112, D02102, doi:10.1029/ 2005JD006558

Swenson, G. R., and A. Z. Liu (1998), A model for calculating acoustic gravity wave energy and momentum flux in the mesosphere from $\mathrm{OH}$ airglow, Geophys. Res. Lett., 25(4), 477-480, doi:10.1029/98GL00132.

Swenson, G. R., M. J. Taylor, P. J. Espy, C. Gardner, and X. Tac (1995), ALOHA-93 measurements of intrinsic AGW characteristics using airborne airglow imager and groundbased NA wind/temperature lidar, Geophys. Res. Lett., 22(20), 2841-2844.

Tang, J., A. Z. Liu, and G. R. Swenson (2002), High frequency gravity waves observed in $\mathrm{OH}$ airglow at Starfire Optical Range, NM: Seasona variations in momentum flux, Geophys. Res. Lett., 29(20), 1966, doi:10.1029/2002GL015794.

Tang, J., G. R. Swenson, A. Z. Liu, and F. Kamalabadi (2005), Observational investigations of gravity wave momentum flux with spectroscopic imaging, J. Geophys. Res., 110, D09S09, doi:10.1029/2004JD004778.

Tao, X., and C. S. Gardner (1995), Heat flux observations in the mesopause region above Haleakala, Geophys. Res. Lett., 22(20), 2829-2832.

Taylor, M. J., E. H. Ryan, T. F. Tuan, and R. Edwards (1993), Evidence of preferential directions for gravity wave propagation due to wind filtering in the middle atmosphere, J. Geophys. Res., 98(A4), 6047-6057, doi:10.1029/92JA02604.

Taylor, M. J., W. R. Pendleton Jr., S. Clark, H. Takahashi, D. Gobbi, and R. A. Goldberg (1997), Image measurements of short-period gravity waves at equatorial latitudes, J. Geophys. Res., 102(D22), 26,283-26,299.

Taylor, M. J., W. R. Pendleton Jr., H.-L. Liu, C. Y. She, L. C. Gardner, R. G. Roble, and V. Vasoli (2001), Large amplitude perturbations in mesospheric $\mathrm{OH}$ Meinel and $87-\mathrm{km} \mathrm{Na}$ lidar temperatures around the autumnal equinox, Geophys. Res. Lett., 28(9), 1899-1902, doi:10.1029/ 2000GL012682

Vargas, F., G. Swenson, A. Liu, and D. Gobbi (2007), $\mathrm{O}\left({ }^{1} \mathrm{~S}\right), \mathrm{OH}$, and $\mathrm{O}_{2}$ (A) airglow layer perturbations due to AGWs, and their implied effects on the atmosphere, J. Geophys. Res., 112, D14102, doi:10.1029/ 2006JD007642.

Vincent, R. A. (1984), Gravity-wave motions in the mesosphere, J. Atmos. Terr. Phys., 46, 119-128, doi:10.1016/0021-9169(84)90137-5.

Walterscheid, R. L., J. H. Hecht, R. A. Vincent, I. M. Reid, J. Woithe, and M. P. Hickey (1999), Analysis and interpretation of airglow and radar observations of quasi-monochromatic gravity waves in the upper meso- 
sphere and lower thermosphere over Adelaide, Australia $\left(35^{\circ} \mathrm{S}, 138^{\circ} \mathrm{E}\right)$, J. Atmos. Terr. Phys., 61, 461-478, doi:10.1016/S1364-6826(99)00002-4.

Wrasse, C. M., et al. (2006), Reverse ray tracing of the mesospheric gravity waves observed at $23^{\circ} \mathrm{S}$ (Brazil) and $7^{\circ} \mathrm{S}$ (Indonesia) in airglow imagers, J. Atmos. Terr. Phys., 68, 163-181, doi:10.1016/j.jastp.2005.10.012.

Wu, Q., and T. L. Killeen (1996), Seasonal dependence of mesospheric gravity waves $(<100 \mathrm{~km})$ at Peach Mountain Observatory, Michigan, Geophys. Res. Lett., 23(17), 2211-2214, doi:10.1029/96GL02168.

Yamada, Y., H. Fukunishi, T. Nakamura, and T. Tsuda (2001), Breaking of small-scale gravity wave and transition to turbulence observed in $\mathrm{OH}$ airglow, Geophys. Res. Lett., 28(11), 2153-2156, doi:10.1029/ 2000GL011945.

Zhao, Y., M. J. Taylor, and X. Chu (2005), Comparison of simultaneous Na lidar and mesospheric nightglow temperature measurements and the effects of tides on the emission layer heights, J. Geophys. Res., 110, D09S07, doi:10.1029/2004JD005115.

M. K. Ejiri and T. Nakamura, Research Institute for Sustainable Humanosphere, Kyoto University, Gokasho, Uji, Kyoto 611-0011, Japan. (mitsumu@rish.kyoto-u.ac.jp)

S. J. Franke, Department of Electrical and Computer Engineering, University of Illinois at Urbana-Champaign, 320 CSL, 1308 West Main Street, Urbana, IL 61801, USA.

M. J. Taylor, Center for Atmospheric and Space Sciences, Utah State University, 4405 Old Main Hill, SER Building, Logan, UT 84322-4405, USA. 